\title{
CONSIDERAÇÕES SOBRE O GESTO DE AUTORIA NA MODERNA GRAMÁTICA PORTUGUESA (1961), DE EVANILDO BECHARA
}

\author{
Thaís de Araujo da Costa* \\ Vanise Gomes de Medeiros** \\ Universidade Federal Fluminense \\ Instituto de Letras \\ Niterói, RJ, Brasil
}

\begin{abstract}
Resumo: Calcado no aporte teórico da Análise de Discurso - Pêcheux e Orlandi - na sua relação com a História das Ideias Linguísticas - Auroux e Orlandi -, este artigo tem por objetivo refletir sobre a produção do gesto de autoria na primeira edição da Moderna Gramática Portuguesa (1961), de Evanildo Bechara. Para tanto, a análise se detém na compreensão dos efeitos produzidos no dizer do gramático pelo comparecimento do termo fonêmica e na depreensão do processo de distinção entre este e o que então se tinha por fonética e fonologia.
\end{abstract}

Palavras-chave: Análise de Discurso. História das Ideias Linguísticas. Gramática. Evanildo Bechara. Autoria.

1 INTRODUÇÃO

A primeira edição da Moderna gramática portuguesa, de Evanildo Bechara, publicada em 1961, começou a ser escrita como uma proposta de atualização da Gramática Expositiva (1907), de Eduardo Carlos Pereira ${ }^{1}$. O objetivo era pôr a gramática de Pereira em conformidade não só com a Nomenclatura Gramatical Brasileira (NGB), implementada em 1959, mas também, segundo Cavaliere (2008), com as novas ideias estruturalistas que chegaram ao Brasil, estabilizando-se no meio universitário através das obras de Mattoso Câmara Jr.. Quando Bechara apresentou à editora o que seria a revisão do primeiro capítulo da gramática de Pereira, no entanto,

\footnotetext{
* Doutoranda em Estudos da Linguagem pela Universidade Federal Fluminense (UFF), sob a orientação da Profa. Dra. Vanise Medeiros. Bolsista CAPES/PDSE - Processo BEX002457/2015-06, cursando estágio doutoral na Université Sorbonne Nouvelle - Paris III, sob a supervisão de Jean-Marie Fournier. Membro do Laboratório Arquivos do Sujeito (LAS) e do Laboratoire d'histoire des théories linguistiques (LAB-HTL). E-mail: araujo_thais@yahoo.com.

${ }^{* *}$ Professora-adjunta da UFF, Bolsa CNPq de Produtividade em Pesquisa (Pesquisador 2; JCNE FAPERJ (2012-2015) e coordenadora do Laboratório Arquivos do Sujeito (LAS) juntamente com Bethania Mariani e Silmara Dela Silva. E-mail: vanisegm@yahoo.com.br.

${ }^{1}$ Eduardo Carlos Pereira falecera em 1923, mas sua gramática, cuja primeira edição data de 1907, continuou a ser editada até 1958 , sendo considerada "um dos maiores sucessos editoriais do livro didático brasileiro" (CAVALIERE, 2008, p. 26). Tratava-se, pois, como explica Orlandi (2002, p. 143), de um compêndio "adotado como referência no ensino da língua nas escolas" que alcançara a marca de 102 edições até então.
} 
este foi reconhecido não como uma atualização, mas como um novo livro, que posteriormente viria ser a primeira edição da Moderna gramática portuguesa (doravante MGP), e isso porque, conforme Orlandi (2002), na sua (re)formulação coloca-se em questão um outro processo de autoria, uma outra função-autor, distinta daquela em que se inscrevia Eduardo Carlos Pereira.

Neste artigo, buscando, então, compreender como as condições de produção em que se deu a (re)formulação da primeira edição da MGP se fazem significar na sua materialidade, propomo-nos, do lugar de encontro da Análise de Discurso - Pêcheux e Orlandi - com a História das Ideias Linguísticas - Auroux e Orlandi -, a tecer algumas reflexões iniciais sobre a relação entre função-autor e forma de gramática ${ }^{2}$ a partir da análise da produção do efeito de distinção no dizer do gramático para o que se tinha à época por estudos fonológicos, fonéticos e fonêmicos.

\section{DE ADAPTADOR A AUTOR: AS CONDIÇÕES DE PRODUÇÃO DA PRIMEIRA EDIÇÃO DA MGP}

Do final do século XIX ao início do século XX, as gramáticas brasileiras buscavam produzir um efeito de distinção entre a língua do Brasil e a de Portugal (ORLANDI, 2002) e, embora fossem empregadas como instrumento de ensino dessa língua que buscavam tornar visível, não eram tão somente normativas, visto que havia materializado nelas um (in)tenso diálogo com os saberes filiados ao que internacionalmente era concebido como ciência(s) da linguagem. Nessa época, destacase a publicação do programa de Fausto Barreto em 1887, a partir do qual, conforme podemos depreender em Guimarães (1997/1996) e Maciel ([1910] 1996), legitimou-se no Brasil a forma de saber associada à gramática histórica e, com isso, impôs-se como determinação histórica a filiação a essa orientação.

Conforme Orlandi (2002), o sucesso da gramática de Pereira não se deu por acaso. Embora a tradição gramatical portuguesa ${ }^{3}$ não deixe de comparecer em seu trabalho, ele, seguindo o caminho aberto por Júlio Ribeiro, dela de certa maneira afasta-se ao buscar conciliar as tendências linguísticas - gramática filosófica e gramática histórica em conflito no território nacional.

Apesar de a Gramática expositiva de Pereira inscrever-se na tradição fílosófica, nela também comparecem, em notas e observações, sentidos filiados à gramática histórica. Como pontua Orlandi (2002), na gramática de Pereira, a questão pedagógica é o que determina a forma da gramática expositiva, sendo o que o autor chama de "dosagem histórica" ministrada enquanto objeto de reflexão e não somente de comodidade didática, como se poderia pressupor. Sendo assim, conclui a autora, na obra de Pereira, "exposição didática e gramática expositiva rimam no modo como, levando em conta, colocam ao lado a gramática histórica como complementar" (ORLANDI, 2002, p. 145).

\footnotetext{
${ }^{2}$ Fazemos referência aqui à Orlandi (2002), quando a autora afirma que a função-autor gramático está relacionada à forma da gramática e ao imaginário de língua que nela comparece. Essa questão será retomada mais adiante.

${ }^{3}$ A chamada tradição gramatical portuguesa que a essa época ainda predominava no Brasil é aquela em que se inscreve a gramática de Jerônimo Soares Barbosa, a qual, por alguns autores, é tomada como o texto mais representativo dessa tradição no Brasil.
} 
As condições de produção em que se iniciou o projeto de atualização da gramática de Pereira são, então, totalmente distintas daquelas que vigoravam no momento de sua (re)edição (de 1907 a 1958). Quando, em 1960, Bechara iniciou o seu processo de escrita, não se tinha mais a tensão entre gramática filosófica e gramática histórica, mas sim entre um certo fazer gramatical que se desenvolveu no Brasil durante o século XIX e o início do século XX - ao qual pertence a gramática de Pereira -, a tradição imposta pela NGB e os estudos filiados à então chamada ciência Linguística. Daí, de acordo com Orlandi (2002, p. 148), Bechara ter sido "reconhecido não como possível adaptador do texto, mas como o autor de outra gramática", o que significa dizer que há uma diferença fundamental no fazer gramatical dos dois autores, isto é, no processo de autoria instaurado em suas gramáticas.

Enquanto Eduardo Carlos Pereira se inscrevia num lugar em que os estudos linguísticos compareciam ao lado dos estudos gramático-normativos de cunho predominantemente pedagógico, Bechara, na sua proposta de atualização da Gramática expositiva, inscreve-se num lugar outro, em que o trabalho do gramático aparece ao lado (i.e., diferenciado) do trabalho do linguista. Ou seja, nas palavras de Orlandi (2002, p. 148), "a gramática de Bechara, ao tentar adaptar a gramática de Eduardo Carlos Pereira à NGB entra em outro processo de autoria, produção de outra função-autor, pois ao fazê-lo distingue o que em Eduardo Carlos Pereira não está distinto", ou seja, o lugar de produção de conhecimento sobre a língua e o lugar de transmissão deste sob a forma de saber da língua.

\section{A AUTORIA NOS COMPÊNDIOS GRAMATICAIS NO SÉCULO XX}

A noção de autoria trabalhada do lugar da AD foi depreendida e deslocada a partir da proposta de Foucault ([1971]2007). Para a AD, assim como para Foucault, o autor pode ser entendido como um "princípio de agrupamento do discurso, como unidade e origem de suas significações, como foco de sua coerência" (FOUCAULT, [1971]2007, p. 26), mas, distanciando-se da proposta deste, a autoria não se restringe a ocasiões especiais em que se dá uma enunciação original. Conforme Orlandi (2007b), existe autoria sempre que um sujeito se coloca (supõe estar) na origem do dizer, produzindo um texto com unidade, coerência, não contradição e fim. Assim sendo, apesar de o autor não instaurar discursividade, como pressupõe a noção foucaultiana, ele produz um lugar de interpretação, em meio a outros lugares possíveis. Em nossa perspectiva, portanto, a autoria é uma função (função-autor) exercida pelo sujeito discursivo que se caracteriza pela "produção de um gesto de interpretação" (ORLANDI, 2007b, p. 97), no qual o autor é colocado como o responsável pelo sentido do que diz, do que formula, produzindo sentido de acordo com as determinações históricas a que está assujeitado e, com isso, significando-se como autor. Trata-se, assim, de uma forma de se posicionar no interior de uma Formação Discursiva (PÊCHEUX, [1975] 2009) ${ }^{4}$. O que entendemos por autor é, pois, a representação, isto é, a imagem produzida para esse posicionamento que aqui chamamos de gesto de autoria.

\footnotetext{
${ }^{4}$ Tomamos as Formações Discursivas (FDs) como regiões de produção de sentido constitutivamente heterogêneas. Ao conjunto de FDs Pêcheux ([1975] 2009, p. 151) chama de "todo complexo com dominante", ressaltando, com isso, que a relação entre essas FDs é marcada pela disputa, pela tensão, visto que há nesse todo uma FD dominante e outras que "determinam a dominação da formação discursiva dominante".
} 
Tal como Orlandi (2002), entendemos que a função-autor tem a ver com a forma da gramática, com o imaginário de língua que nela comparece e, por conseguinte, com as relações estabelecidas não só entre essa língua e os sujeitos falantes, mas também entre estes. Desse modo, visando compreender o funcionamento da autoria na primeira edição da MGP, adotando como dispositivo de leitura o trajeto temático (GUILHAUMOU; MALDIDIER, 2010) ${ }^{5}$, partimos da leitura do prefácio ${ }^{6}$, buscando depreender dois pontos: 1) a constituição da forma de gramática que se instaura após a implementação da NGB e 2) o efeito no discurso gramatical da projeção no Brasil do que se tem por ciência Linguística.

A tensão entre o que se coloca como da ordem do novo e da ordem do tradicional é recorrente ao longo do prefácio da primeira edição da Moderna Gramática Portuguesa e está estreitamente ligado à configuração dos espaços destinados à ciência e ao ensino, à universidade e à escola, ou, em outras palavras, à distinção entre o lugar do gramático e o do linguista. Em seu prefácio, a MGP é caracterizada como um "compêndio escolar" que tem por objetivo levar "aos colegas do magistério, aos alunos e quantos mais se interessam pelo ensino e aprendizado do idioma" o que à época se tem por "resultado dos progressos que os modernos estudos da linguagem alcançaram no estrangeiro e no país" (BECHARA, 1961, p. 21).

A estes "modernos estudos da linguagem" opõe-se, conforme o prefácio, o que é posto como "tradição secular", à qual se filia, por sua vez, o que é colocado como "modelo clássico" - "Não se rompe de vez com a tradição secular: isto explica por que esta Moderna Gramática traz uma disposição da matéria mais ou menos conforme o modêlo clássico" (BECHARA, 1961, p. 21) ${ }^{7}$. Para essa tradição é produzido um sentido de defasagem que torna impossível a manutenção da sua adoção - "muitos assuntos importantes que não poderiam continuar a ser encarados pelos prismas por que a tradição os apresentava" (BECHARA, 1961, p. 21) -, ao passo que os modernos estudos são colocados como o "tratamento novo" que se fez necessário dispensar a esses assuntos.

Observemos também nessa formulação uma primeira justificativa para o título do compêndio. Ele é 'moderno' porque leva "o resultado dos progressos que os modernos estudos de linguagem alcançaram no estrangeiro e em nosso país". Esse sentido de progresso, de novidade, no entanto, não é colocado como concernente à disposição da matéria, pelo menos não em sua totalidade, pois, nesse aspecto, diz-se que a MGP não rompe "de vez" com o que é posto como "tradição secular", apresentando-a "mais ou menos" conforme o chamado "modelo clássico". Chamamos atenção aqui para o funcionamento das expressões "de vez" e "mais ou menos". Se não rompe "de vez" com o que é posto como "tradição secular", pressupõe-se que rompe em parte; e se a gramática se apresenta "mais ou menos" em conformidade com o que se coloca como "modelo clássico", é porque dele em algum ou em alguns aspectos (pressupõe-se que)

\footnotetext{
5 O trajeto temático, enquanto dispositivo de leitura, funciona como fio condutor que nos permite agrupar/organizar, em eixos de análise, diferentes enunciados que, determinados historicamente, se entrecruzam em nosso objeto.

${ }^{6}$ Para um estudo discursivo dos prefácios ver Orlandi (2008a).

${ }^{7}$ Nas transcrições das sequências analisadas, mantivemos a ortografia original.
} 
se distancia. A primeira edição da MGP traz, assim, em seu prefácio, uma tensão entre o mesmo e o diferente, entre manutenção e ruptura, a partir da qual se impuseram à nossa leitura as seguintes perguntas: com o que (não) se pode e (não) se deve romper nessa conjuntura? E o que (não) se pode e (não) se deve manter do chamado "modelo clássico"? O que se diz quando se diz "modernos estudos da linguagem" ou "tradição secular"?

Ainda no prefácio da primeira edição da MGP, a forma de saber denominada linguística americana, cujos estudos são significados como excelentes, é relacionada aos termos "fonêmica" e "estilística". Nele materializa-se também a aquiescência à Nomenclatura Gramatical Brasileira $(\mathrm{NGB})^{8}$, à qual, no entanto, é atribuído um sentido de falta - "Os têrmos que aqui se encontram e lá faltam, não se aplicarão por discordância ou desrespeito; é que a NGB não tratou de todos os assuntos aqui ventilados" (BECHARA, 1961, p. 22, grifo nosso) - que justifica o comparecimento de outros termos, para além daqueles instituídos pela terminologia oficial, no dizer do gramático.

Por fim, cabe ressaltar, que, no prefácio em questão, a orientação científica que norteia a MGP é colocada como advinda da "lição" daqueles que se tem por "mestres" de "dentro e fora do país", dentre os quais é citado como exemplo, a quem inclusive é dedicada à gramática de Bechara, Said Ali. Com isso, parece colocar-se em relação com o que se tem por "modernos estudos" a forma de saber à qual se filia o nome de autor Said Ali, notadamente a filologia, a qual, então, figuraria ao do lado do que, como dissemos, é posto como fonêmica, análise estilística e linguística americana.

\section{O NOVO E O TRADICIONAL NO DIZER DO GRAMÁTICO}

Embora para se instituir lance mão do argumento de cientificidade (ORLANDI, 2002), ao se inscrever na história dos estudos linguístico-gramaticais no/do Brasil, a NGB, em função da distinção procedida entre gramática e linguística, é circunscrita ao domínio da primeira, significando-se/sendo significada como a tradição gramatical brasileira. Assim é que, como vimos, no prefácio da primeira edição da MGP, a ela é atribuído um sentido de falta que autoriza ao gramático mobilizar sentidos não instituídos/legitimados em/por seu texto.

Além desse sentido de falta atribuído à terminologia oficial, o gramático mobiliza, em seu prefácio, o que é posto como "modernos estudos gramaticais", aos quais, como pontuamos, se filiam diferentes formas de saber, tais quais: estilística, linguística americana, filologia e fonêmica. Como anunciamos, neste artigo buscaremos compreender os efeitos produzidos pelo comparecimento desse último termo no dizer do gramático, bem como o efeito de distinção que se estabelece entre ele e o que então se tinha por fonética e fonologia.

\footnotetext{
${ }^{8}$ Lembremos aqui que a implementação da NGB, em 1959, foi um dos motivos por que Bechara foi convidado para adaptar a gramática de Eduardo Carlos Pereira. Para um estudo discursivo da NGB ver Baldini (2009) e Costa (2010).
} 
O projeto da NGB (1959) divide a gramática em três partes: Fonética, Morfologia e Sintaxe, e acrescenta como apêndice: Figuras de sintaxe, Gramática Histórica, Ortografia, Pontuação, Significação das palavras e Vícios de linguagem. Orlandi (2002, p. 148), comentando a distinção entre o processo de autoria instaurado na MGP e o que se dá na Gramática Expositiva de Pereira, assinala que naquela diferentemente do que se tem nesta, em que os estudos fonológicos incluem-se, assim como os morfológicos, no capítulo intitulado Lexicologia, à Fonética/Fonêmica é destinado um lugar de maior "independência e realce", seguindo a ordem predeterminada pela NGB, isto é, configurando-se como um capítulo independente, ao lado da Morfologia e da Sintaxe.

Aqui cabe destacar que em Pereira (1907) comparece, ao lado de Morfologia, como estudo subordinado à Lexicologia, o termo Fonologia, mas tanto na NGB como na MGP o termo que comparece é Fonética e, na última, ao seu lado, também Fonêmica. Para nós, como explicaremos adiante, essa substituição é significativa, por isso passaremos, ao nos referirmos a essa(s) forma(s) de saber, a trabalhar a tensão entre esses termos e, por conseguinte, entre os saberes que eles mobilizam.

Segundo Orlandi (2002, p. 148), a distinção entre Fonologia/Fonética/Fonêmica e Morfologia $^{9}$, de modo que elas se tornem coisas independentes e não parte de um mesmo tema: a Lexicologia, "mostra como a forma da gramática tem que ver com a forma da função-autor gramático e como isso tem consequências sobre o trabalho produzido pelo gramático na relação do sujeito com sua língua". Com isso, a autora chama-nos atenção para o fato de que na forma da gramática materializam-se sentidos predominantes no momento de sua formulação, mas não só esses.

De acordo com Orlandi (2008b), as condições de produção de um dizer não se restringem ao momento de sua formulação, o que poderia sugerir equivocadamente a restrição desse conceito ao de contexto imediato. Em função disso, em nossa análise, consideramos também o momento de circulação e o processo de constituição do discurso, isto é, o modo como a memória desse dizer nele se faz significar, memória esta que, no caso em análise, é pelo menos até certo ponto comum aos dois compêndios. Dissemos "até certo ponto" porque, após a morte de Pereira, temos três acontecimentos que incidiram diretamente sobre essa memória e, portanto, sobre as condições de produção do discurso gramatical brasileiro, a saber: 1) a disposição normativa da Lei 4.024/61 (LDB) sobre a organização do ensino, 2) a implementação da NGB, por meio da Portaria $\mathrm{N}^{\mathrm{o}} 36$ de 1959, e 3) a assunção da ciência Linguística no Brasil a partir de meados do século XX. Assim, tal como Orlandi (2002), entendemos que o que diferencia a gramática de Bechara e a de Pereira são as redes de relações a que elas se filiam, filiações estas que estão diretamente ligadas ao momento de formulação desses compêndios. Daí considerarmos que, ao se significarem/serem significadas no discurso gramatical brasileiro, as gramáticas de Pereira e de Bechara significam(-se) diferentemente.

\footnotetext{
9 Orlandi (2002) diz entre fonologia e sintaxe, mas em Pereira (1907), nos estudos lexicológicos, encontra-se ao lado da fonologia a morfologia e, numa parte independente, a sintaxe.
} 
Além da distinção em relação ao que postula a terminologia oficial apontada anteriormente, Bechara, no prefácio à primeira edição da MGP, afirma trazer para o seu compêndio "noções, ainda que breves, sobre fonêmica" (BECHARA, 1961, p. 21), mas essa expressão não comparece no projeto da NGB. Assim sendo, tornou-se necessário para nós em nossa investigação compreendermos o modo como a abordagem dessa forma de saber denominada Fonêmica contorna o discurso oficial, legitimando o seu comparecimento.

\title{
4.2 DA DISTINÇÃO ENTRE OS ESTUDOS FONOLÓGICOS, FONÉTICOS E FONÊMICOS
}

Como nos explica Mattoso Câmara Jr. ([1975] s.d.), o termo "fonêmica" foi cunhado pela escola linguística norte-americana, cujos nomes de referência são Edward Sapir e Leonard Bloomfield. Esse termo comparece, na primeira edição da Moderna gramática portuguesa, em "Fonética descritiva", no capítulo intitulado "Fonética e Fonêmica", no qual há uma seção homônima. Nesta seção, diz o gramático:

\begin{abstract}
Na atividade linguística, o importante para os falantes é o som, e não a série de movimentos articulatórios que o determina. Assim sendo, enquanto a análise fonética se preocupa tãosòmente com a articulação, a fonêmica atenta apenas para o som que, reunindo um feixe de traços que o distingue de outro som, permite a comunicação linguística. A fonética pode reconhecer, e realmente o faz, diversas realizações para o /t/ da série ta-te-ti-to-tu; a fonêmica não leva em conta as variações (que se chamam alofones), porque delas não tomam conhecimento os falantes de língua portuguesa. Um fonema admite uma gama variada de realizações fonéticas que vai até a conservação da integridade do vocábulo: quando isto não ocorre, diz-se que houve mudança de fonema. $\mathrm{O} / 1 /$ admite várias realizações no Brasil, de norte a sul (e estas variantes não interessam à análise fonêmica, que deveria ter primazia em nosso estudo de língua); mas haverá mudança de fonemas quando se não puder fazer a oposição $\mathrm{mal} / \mathrm{mau}$. Como bem ensina Matoso Câmara, "o fonema, entendido como um feixe de traços distintivos, individualiza-se e ganha realidade gramatical pelo seu contraste com outros feixes em idênticos ambientes fonéticos. Não é, pois, a diferença articulatória e acústica que distingue primariamente dois fonemas, senão a possibilidade de determinarem significações distintas numa mesma situação fonética. Compreende-se assim que um mesmo fonema possa variar amplamente na sua realização, conforme o ambiente fonético ou as peculiaridades do sujeito falante".

Fonêmica não se opõe a fonética: a primeira estuda o número de oposições utilizadas e suas relações mútuas, enquanto a fonética experimental determina a natureza física e fisiológica das distinções observadas. (BECHARA, 1961, p. 28, itálicos do autor, grifos nossos).
\end{abstract}

Como se pode ver na sequência acima, produz-se na MGP (1961) um efeito de distinção entre as formas de saber Fonêmica e Fonética ("enquanto a análise fonética se preocupa tão-sòmente com a articulação, a fonêmica atenta apenas para o som que, reunindo um feixe de traços que o distingue de outro som, permite a comunicação linguística”). Coloca-se, contudo, que, apesar de distintas, essas formas de saber não são opostas ("Fonêmica não se opõe a fonética"). Cabe aqui chamarmos atenção ainda para o mecanismo de citação empregado para justificar a inclusão desse campo de saber em seu compêndio: primeiramente trazendo a noção de fonema formulada por Câmara Jr. e, em seguida, fazendo referência, em nota de rodapé colocada no final do último 


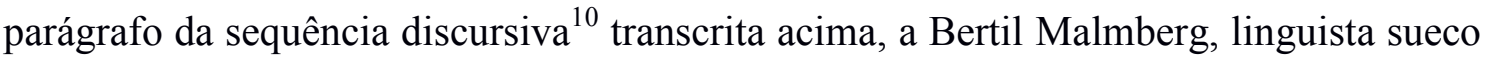
autor de La Phonétique.

Para melhor compreendermos a tensão que mencionamos anteriormente entre os termos fonologia, fonética e fonêmica, retomaremos aqui algumas considerações de Câmara Jr. ([1975] s.d.), em sua História da Linguística. De acordo com Câmara Jr., até meados do século XIX, situada no lugar das chamadas ciências naturais, a fonética consistia num estudo biológico da linguagem e era significada como uma "disciplina auxiliar da linguística", cujas complexidades físicas e fisiológicas os linguistas deveriam estudar e dominar para serem capazes de "lidar com os sons vocais e suas mutações" (CÂMARA JR., [1975] s.d., p. 83). Somente com o trabalho do alemão Eduard Sievers (1876), segundo o autor, a fonética teria passado a ser concebida como uma ramificação dos estudos linguísticos, mais especificamente com o desenvolvimento dos estudos fonéticos de base comparativa, notadamente aqueles relacionados ao indoeuropeu. Nas primeiras décadas do século XX, contudo, ainda conviviam com os estudos fonético-linguísticos outros a partir dos quais a fonética era significada pelos linguistas como uma disciplina auxiliar.

Entendia-se, então, que esses estudos, embora também fossem de grande utilidade para os linguistas por lhes proporcionarem uma compreensão mais profunda do mecanismo da fala, afastavam a fonética da disciplina linguística, pois da maneira como estavam sendo desenvolvidos cada vez mais se aproximavam das chamadas ciências naturais, ao passo que, já a esta época, o conceito de língua enquanto sistema de sinais, difundido a partir de Marty e Saussure, significava os estudos da linguagem no âmbito das ciências humanas.

Foi, pois, Saussure que, como relata Câmara Jr. ([1975] s.d.), retomando o conceito de fonema enquanto sons vocais proposto pelo linguista polaco Jan Baudouin de Courtenay (1845-1929), ao inseri-lo na sua teoria geral e essencial dos sinais linguísticos, finalmente conseguiu delinear esses estudos dentro da ciência linguística. Entendendo que muitas questões acústicas e articulatórias levantadas até então eram irrelevantes para a comunicação linguística, o linguista genovês estendeu à fonética o princípio de oposições linguísticas, sobre o qual se fundamenta a sua concepção de língua, assinalando que o fonema é importante para os estudos linguísticos somente na medida em que se difere de outros fonemas.

Em 1928, no Primeiro Congresso Internacional de Linguística, realizado em Haia, estudiosos do Círculo Linguístico de Praga (Troubetzkoy, Jakobson e Karcevski), na sua primeira aparição na Europa, apresentaram uma comunicação em que refletiram sobre os métodos mais convenientes para "uma descrição prática e completa da gramática de uma língua" (CÂMARA JR, [1975] s.d., p. 210). Na ocasião, eles trouxeram à baila o conceito de entidades linguísticas e propuseram a distinção entre dois tipos de estudo: a fonética, concebida como uma ciência natural, e a fonologia, concebida enquanto uma ramificação da linguística que "trata da significação dos traços fonéticos em uma língua” (CÂMARA JR, [1975] s.d., p. 210), enfatizando-se, como

\footnotetext{
${ }^{10}$ As sequências discursivas são, conforme Orlandi (1984), unidades discursivas de textos de natureza variada que se configuram enquanto fragmentos de uma dada situação discursiva postos em correlação conforme a pergunta feita pelo analista, a partir de uma dada posição teórica.
} 
justificativa para legitimação desta última, a necessidade, em conformidade com a proposta de Saussure, de se estabelecer um sistema de oposição de sons linguisticamente significativos e a relevância da correlação entre esses sons para se explicar a mudança fonética (fonologia diacrônica).

Mais ou menos na mesma época, de acordo com Câmara Jr. ([1975] s.d.), o linguista americano Edward Sapir vinha desenvolvendo, com fundamentação de base psicológica e formalista, uma visão padronizada da língua que o levou, por não aceitar a ideia de que os sons vocais eram tão somente realizações físicas, a buscar estabelecer um padrão intrínseco para eles. Em seu artigo intitulado "Padrões fonológicos", a distinção entre o que é produzido pelos órgãos fonadores do homem e o que é por ele reconhecido como linguisticamente significativo ganha, então, corpo. A noção de "padrão fonológico da língua" formulada nesse artigo parte do princípio de que há uma padronização fonética de base "psicológica intuitiva que se superpõe às diferenças físicas do som” (CÂMARA JR., [1975] s.d., p. 207). Esse padrão formado de pontos linguisticamente significativos assemelha-se, num primeiro momento, conforme Câmara Jr. ([1975] s.d.), à concepção de sistema de fonemas, formulado por Troubetzkoy, estudioso do Círculo de Praga, de tal modo que por fim Sapir resolve-se também por adotar o termo "fonema". Embora a descrição proposta por Sapir se aproximasse quanto ao sincronismo dos estudos de Saussure, destes se distanciava em função da concepção de que a mudança está essencialmente ligada à estrutura linguística. Considerando os estudos diacrônicos do ponto de vista formal, Sapir rejeitava também a separação proposta pelos neogramáticos entre mudança fonética e mudança morfológica, pois para ele a mudança deve ser encarada como um todo no qual se entrelaçam motivações de ambos os tipos. É, portanto, nesse sentido que propõe a noção de impulso, segundo a qual não há casualidade nas mudanças linguísticas, mas antes uma determinação dos padrões da língua que se desenvolvem incessantemente.

A descrição formalista proposta por Sapir, mais especificamente o seu conceito de padrões fonológicos, foi o que proporcionou o terreno fértil para que fossem assentadas no livro Language (1933), de autoria de seu amigo Leonard Bloomfield, as bases da teoria fonêmica. É nesse livro que Bloomfield, conforme Câmara Jr. ([1975] s.d., p. 212), aproximando-se do conceito formulado pelos estudiosos do Círculo de Praga, define fonema como "um feixe de traços distintivos dentro do complexo do som vocal". Com isso, o linguista americano fundamenta teoricamente o desenvolvimento da "fonêmica", teoria que, para Câmara Jr. ([1975] s.d., p. 212), consiste numa "réplica americana para a 'fonologia' de Troubetzkoy"'

São três, conforme Câmara Jr. ([1975] s.d.), as principais distinções entre os estudos americanos e aqueles desenvolvidos na Escola de Praga, a saber: 1) nesses últimos compareciam os conceitos de "Neutralização" e "Arquifonema", os quais não foram contemplados no trabalho de Bloomfield; 2) Bloomfield era cético em relação à concepção proposta pelos estudiosos de Praga da fonética enquanto ciência; e 3) a

\footnotetext{
${ }^{11}$ Sobre a origem do termo fonêmica, comenta Câmara Jr. ([1975] s/d, p. 212): "Bloomfield não é o criador do termo 'fonêmica' que foi criticado como 'espúrio', uma vez que a derivação normal, de acordo com a formação da palavra em grego, requereria fonemática, mas empregou o termo fonêmico como adjetivo".
} 
chamada fonêmica americana, em função dessa rejeição, diferentemente do que na Europa se colocava como fonologia, passou a dar maior destaque à técnica distribucional, o que acarretou uma sensível diferença no que tange à concepção de fonema: em vez de ser concebido em função de seus traços fonéticos, ele passou a ser definido de acordo com a posição assumida nas formas linguísticas e com o modo como se combina com outros fonemas.

A partir das contribuições de Câmara Jr. ([1975] s.d.), podemos dizer que:

a) A chamada teoria fonêmica nasce, em última instância, da tensão evidenciada em meados do século XIX entre a abordagem dita biológica (filiada às ciências naturais) e a dita linguística (filiada às ciências sociais), as quais se encontravam em disputa pela chancela da teoria fonética. Tal tensão, como vimos, ainda se faz significar em Bechara, na década de 60 do século XX, quando este afirma que "Na atividade linguística, o importante para os falantes é o som, e não a série de movimentos articulatórios que o determina" (BECHARA, 1961, p. 28, grifo nosso).

b) $\mathrm{O}$ efeito de distinção entre essas duas abordagens ganha embasamento nos dizeres de Saussure e se naturaliza a partir dos trabalhos desenvolvidos do lugar dos estudiosos da Escola de Praga, nos quais se propõe a diferenciação entre dois campos de saber: a Fonética e a Fonologia.

Embora Câmara Jr. ([1975] s.d.) atribua ao Círculo de Praga a proposta de distinção entre esses dois campos, no Curso de Linguística Geral (CLG) de Saussure ([1916] 2006), já encontramos uma certa proposta de diferenciação:

\begin{abstract}
A fisiologia dos sons (...) é frequentemente chamada de 'Fonética' (...). Êsse têrmo nos parece impróprio; substituímo-lo por Fonologia. Pois Fonética designou a princípio, e deve continuar a designar, o estudo das evoluções dos sons; não se deveriam confundir no mesmo título dois estudos absolutamente distintos. A Fonética é uma ciência histórica; analisa acontecimentos, transformações e se move no tempo. A Fonologia se coloca fora do tempo, já que o mecanismo de articulação permanece sempre igual a si mesmo.

Longe de se confundir, êsses dois estudos nem sequer podem ser postos em oposição. O primeiro é uma das partes essenciais da ciência da língua; a Fonologia, cumpre repetir, não passa de disciplina auxiliar e só se refere à fala. (SAUSSURE, [1916] 2006, p. 42-43, grifos nossos).
\end{abstract}

Ainda que os estudiosos da Escola de Praga, em 1928, ao formalizarem a distinção entre esses dois campos de saber tenham levado em consideração a proposta de Saussure no que tange à necessidade de estabelecimento de um sistema de oposição de sons linguisticamente significativos, como podemos ver na sequência acima os sentidos atribuídos a esses campos são contraditórios nas duas propostas.

Para Saussure (CLG), a Fonologia é a "fisiologia dos sons" e, por isso, considerando que o mecanismo de articulação desses não muda, entende-se que ela se coloca "fora do tempo". Daí ser, por só se referir à fala, considerada como uma "disciplina auxiliar" da ciência Linguística. Já a Fonética constitui-se como "uma ciência histórica", que "analisa acontecimentos, transformações e se move no tempo", o 
que a caracteriza como - e aí, tendo em vista a cisão instaurada a partir de seus estudos entre sincronia e diacronia, chamamos atenção para uma contradição em sua proposta "uma das partes essenciais da ciência da língua".

Para os estudiosos do Círculo de Praga, como vimos, contudo, os sentidos atribuídos a esses termos opõem-se à proposta saussuriana. Enquanto, desse lugar, a Fonética consiste num estudo que se dá no domínio das ciências naturais, a Fonologia, considerada como uma abordagem que "trata da significação dos traços fonéticos em uma língua", consiste numa ramificação da ciência Linguística.

Faz-se aqui preciso observar alguns pontos. Nessas duas propostas de distinção materializa-se a disputa que mencionamos em a), segundo a qual, dependendo do lugar de onde se fala, os estudos fonéticos/fonológicos ora são significados como próprios às ciências naturais, constituindo-se como uma ferramenta auxiliar no fazer do linguista, ora como próprios à então chamada ciência Linguística. Note-se também uma tensão no que concerne ao sentido desses termos: qual estaria associado a uma abordagem biológica dos sons e qual estaria associado a uma abordagem linguística? Desfeita essa confusão, foram, pois, os sentidos que compareceram nos trabalhos dos estudiosos da Escola de Praga para os termos fonética e fonologia que se naturalizaram nos estudos da linguagem desenvolvidos no Brasil.

A despeito dessa contradição, faz-se preciso esclarecer que já em Saussure temos a materialização de um efeito de distinção entre os estudos fonéticos e fonológicos ("Longe de se confundir (...)"). Em seu texto já comparecem sentidos que sugerem que o que se faz de um lugar não equivale ao que se faz do outro. Além disso, evidencia-se também a não existência de oposição entre esses dois tipos de estudos ("êsses dois estudos nem sequer podem ser postos em oposição"), sentido este que, como vimos, também comparece em Bechara (1961).

No quadro 1, apresentado mais adiante, sintetizamos o que foi visto até aqui.

c) Como pode ser observado no quadro 1, além de uma disputa que surge em meados do século XIX entre as áreas de conhecimento a que estariam filiados os estudos fonéticos/fonológicos (se às ciências naturais ou às sociais), bem como entre os sentidos associados aos termos Fonética e Fonologia, como vimos em Sausurre (CLG) e nos estudiosos do Círculo de Praga, observa-se, na década de 30 do século XIX, com o desenvolvimento da linguística americana, mais especificamente com os estudos bloomfieldianos, o comparecimento de um outro nome que passa a se relacionar de forma tensa com aqueles. Enquanto desse lugar a Fonética não é tomada enquanto ciência, o termo Fonêmica passa a nomear os estudos dos sons desenvolvidos no âmbito da Linguística, instaurando-se, assim, uma relação de disputa entre este e o termo Fonologia, conforme concebido pelo Círculo Linguístico de Praga. 
Quadro 1 - Tensão entre fonética, fonêmica e fonologia

\begin{tabular}{|c|c|c|c|c|c|c|}
\hline $\begin{array}{c}\text { Meados } \\
\text { do século } \\
\text { XIX }\end{array}$ & $\begin{array}{c}\text { Final do } \\
\text { século XIX }\end{array}$ & $\begin{array}{c}\text { Sausurre } \\
\text { (CLG, 1916) }\end{array}$ & $\begin{array}{c}\text { Círculo } \\
\text { Linguístico de } \\
\text { Praga } \\
(\mathbf{1 9 2 8 )}\end{array}$ & $\begin{array}{c}\text { Linguística } \\
\text { americana } \\
\text { Sapir/ } \\
\text { Bloomfield } \\
(1933) \\
1^{\circ} \text { Momento }\end{array}$ & $\begin{array}{c}\text { Linguística } \\
\text { americana } \\
\text { Bloomfield } \\
2^{\circ} \text { momento }\end{array}$ & $\begin{array}{c}\text { Bechara } \\
\text { (1961) }\end{array}$ \\
\hline $\begin{array}{c}\text { Fonética } \\
\text { Disciplina } \\
\text { auxiliar da } \\
\text { linguística } \\
\text { filiada às } \\
\text { ciências } \\
\text { naturais }\end{array}$ & $\begin{array}{l}\text { Fonética } \\
\text { Disciplina } \\
\text { auxiliar da } \\
\text { linguística } \\
\text { filiada às } \\
\text { ciências } \\
\text { naturais }\end{array}$ & $\begin{array}{c}\text { Fonologia } \\
\text { Disciplina } \\
\text { auxiliar da } \\
\text { linguística } \\
\text { voltada para } \\
\text { o estudo da } \\
\text { fisiologia dos } \\
\text { sons; } \\
\text { Ciência a- } \\
\text { histórica }\end{array}$ & $\begin{array}{c}\text { Fonética } \\
\text { Ciência natural }\end{array}$ & $\begin{array}{l}\text { Fonética } \\
\text { Não é uma } \\
\text { ciência }\end{array}$ & $\begin{array}{l}\text { Fonética } \\
\text { Não é uma } \\
\text { ciência }\end{array}$ & $\begin{array}{c}\text { Fonética } \\
\text { Preocupa-se } \\
\text { tão somente } \\
\text { com a } \\
\text { articulação }\end{array}$ \\
\hline --- & $\begin{array}{c}\text { Fonética } \\
\text { Ramificação da } \\
\text { Linguística } \\
\text { (estudos } \\
\text { histórico- } \\
\text { comparativos) }\end{array}$ & $\begin{array}{c}\text { Fonética } \\
\text { Ramificação } \\
\text { da } \\
\text { Linguística; } \\
\text { Ciência } \\
\text { histórica } \\
\text { (diacronia); } \\
\text { Mudanças } \\
\text { fonéticas; } \\
\text { Princípio de } \\
\text { oposições } \\
\text { linguísticas }\end{array}$ & $\begin{array}{c}\text { Fonologia } \\
\text { Ramificação da } \\
\text { Linguística; } \\
\text { Princípio de } \\
\text { oposições } \\
\text { linguísticas; } \\
\text { Mudanças } \\
\text { fonéticas/fono- } \\
\text { logia diacrônica }\end{array}$ & $\begin{array}{c}\text { Fonêmica } \\
\text { Ramificação da } \\
\text { Linguística; } \\
\text { Princípio de } \\
\text { oposições; } \\
\text { Mudança } \\
\text { fonética e } \\
\text { morfológica }\end{array}$ & $\begin{array}{c}\text { Fonêmica } \\
\text { Ramificação } \\
\text { da Linguística; } \\
\text { Técnica } \\
\text { distribucional }\end{array}$ & $\begin{array}{l}\text { Fonêmica } \\
\text { Atenta apenas } \\
\text { para o som } \\
\text { que, reunindo } \\
\text { um feixe de } \\
\text { traços que o } \\
\text { distingue de } \\
\text { outro som, } \\
\text { permite a } \\
\text { comunicação } \\
\text { linguística }\end{array}$ \\
\hline
\end{tabular}

Para que se melhor compreenda a tensão que estamos sinalizando aqui, evoquemos a primeira tese postulada por Pêcheux ([1975] 2009) para comprovar o que coloca como o caráter material do sentido segundo o qual não há sentido literal (v. Capítulo I). De acordo com Pêcheux, palavras, expressões e proposições adquirem sentido conforme o posicionamento do sujeito numa dada FD. Assim sendo, podemos distinguir três situações em que se pode observar a tensão entre o mesmo e o diferente, entre paráfrase e polissemia (ORLANDI, 2007a), tensão esta que é inerente a todo e qualquer dizer. Na primeira, uma mesma palavra, expressão ou proposição pode receber sentidos distintos - todos da mesma maneira evidentes - segundo a filiação do sujeito a esta ou aquela FD. Voltando ao quadro 1, poderíamos dizer que esse é o caso do termo fonética no final do século XIX, momento em que se dá a oposição entre os estudos que sob esse nome estão veiculados às ciências naturais e aqueles que estão veiculados à ciência linguística. Poderíamos nessa situação considerar ainda os sentidos dos termos fonética e fonologia para Saussure e para os estudiosos do Círculo de Praga e o sentido da palavra fonética para estes e para os estudiosos filiados à linguística americana.

Se considerarmos a relação estabelecida entre os diferentes domínios a partir dos quais essas palavras são significadas, bem como o gesto de interpretação procedido pelos sujeitos filiados a um domínio em relação ao que é posto como da ordem de outro domínio, teremos de pensar esses distintos sentidos enquanto deslocamentos promovidos em função da passagem de uma FD a outra. A essa ruptura dos processos de significação chamamos polissemia (ORLANDI, 2007a). Em ambas as situações, as palavras são as mesmas (paráfrase), mas os sentidos são outros (polissemia) e se constituem conforme a identificação dos sujeitos a um dado domínio de saber, i.e., a uma dada FD. 
Uma terceira situação nos é ainda trazida por Pêcheux para descrever o caráter material do sentido. Nela, "palavras, expressões e proposições literalmente diferentes podem, no interior de uma formação discursiva dada, "ter o mesmo sentido" (PÊCHEUX, [1975] 2009, p. 148) [itálico do autor]. Como vimos, do lugar de onde diz Câmara Jr. ([1975] s/d), a tensão entre os sentidos atribuídos ao termo fonêmica e fonologia, apesar das diferenças existentes entre o que se faz do lugar, respectivamente, dos estudiosos filiados à escola linguística americana e daqueles filiados à escola de Praga, é silenciada pela imposição de um efeito de equivalência entre esses dois campos. Conforme o linguista, a noção de pontos que formam os chamados padrões fonológicos "é equivalente à concepção de sistema de fonemas na doutrina de Troubetzkoy" (CÂMARA JR., [1975] s.d., p. 207), e a teoria fonêmica, de Bloomfield, configura-se como "uma réplica americana da teoria fonológica do Círculo de Praga" (CÂMARA JR., [1975] s.d., p. 209, grifos nossos).

Nesse sentido, faz-se preciso destacar que o comparecimento do termo fonêmica, em vez de fonologia, como se dá em Eduardo Carlos Pereira, materializando, assim, a sua identificação aos estudos desenvolvidos na Europa, evidencia a filiação de Bechara ao conhecimento sobre língua produzido a partir do lugar da escola linguística americana. No entanto, como todo dizer, como dissemos, se dá na tensão entre o mesmo e o diferente, ao mobilizar, por meio do mecanismo de citação, a definição de fonema que comparece no livro Para o estudo da fonêmica portuguêsa, de Mattoso Câmara Jr., é colocada em funcionamento na primeira edição da MGP uma rede de filliações atravessada pela tensão entre os sentidos associados aos termos fonética, fonêmica e fonologia, como podemos observar no quadro 2 .

\section{Quadro 2 - Da definição de fonema12}

\begin{tabular}{|l|l|}
\hline Bechara & $\begin{array}{l}\text { "o fonema, entendido como um feixe de traços distintivos, individualiza-se e ganha } \\
\text { realidade gramatical pelo seu contraste com outros feixes em identicos ambientes } \\
\text { fonéticos" (CÂMARA JR. apud BECHARA, 1961, p. 28) }\end{array}$ \\
\hline Câmara Jr. & $\begin{array}{l}\text { Feixe de traços distintivos, individualiza-se e ganha realidade gramatical pelo seu } \\
\text { contraste com outros feixes em idênticos ambientes fonéticos. (apud BECHARA, } \\
\text { 1961, p. 28) }\end{array}$ \\
\hline Bloomfield & $\begin{array}{l}\text { Feixe de traços distintivos dentro do complexo do som vocal. (apud CÂMARA JR., } \\
{[1975] \text { s/d, p. 212). }{ }^{13}}\end{array}$ \\
\hline Troubetzkoy & $\begin{array}{l}\text { Sons linguisticamente significativos que constituem um sistema de oposições em } \\
\text { Conformidade com o princípio de oposições linguísticas de Saussure. (apud } \\
\text { CÂMARA JR., [1975] s/d, p. 210) }\end{array}$ \\
\hline
\end{tabular}

\footnotetext{
${ }^{12}$ As definições atribuídas a Bloomfiel e a Troubetzkoy neste quadro foram formuladas a partir de nossa leitura do movimento de leitura de Mattoso Câmara Jr., em História da Linguística ([1975] s/d). Nas notas que se seguem, porém, trazemos as definições de fonema conforme propostas por esses autores, respectivamente, em Language ([1933] 1956) e Principes de Phonologie ([1939] 1949).

${ }^{13}$ Ao analisar a palavra pin (alfinete, em inglês), Bloomfiled conclui que ela tem como traços distintivos três unidades indivisíveis, denominadas fonemas, que podem ocorrer em outras combinações, mas que não devem ser analisadas a partir de semelhanças parciais: "we conclude that the distinctive features of this word are three indivisible units. Each of these units occurs also in other combinations, but cannot be further analyzed by partial resemblances: each of the three is a minimum unit of distinctive soundfeature, a phoneme" ([1933]1956, p. 79).

${ }^{14}$ No livro Principes de phonologie, de Troubetzkoy, o fonema é, primeira e metaforicamente, definido como traços distintivos da silhueta das palavras, que são compreendidas como um todo fônico. Diz o autor: "Chaque mot est plutôt un tout phonique, et les auditeurs le reconnaissent comme une silhouette [...]. Mais la reconnaissance de la silhouette suppose qu'elle se distingue des autres et cela n'est possible que si les diverses silhouettes se distinguent entre elles par certaines marques. Les phonèmes sont donc
} 
Considerando o processo parafrástico como aquele que nos permite depreender no dizer algo que se mantém, i.e., que constitui a sua memória, podemos afirmar que a definição de Câmara Jr. de fonema enquanto "feixe de traços distintivos", retoma pelo mecanismo de citação parafrástica a definição de fonema proposta, num primeiro momento, por Bloomfield, que, por sua vez, consiste numa paráfrase da definição formulada por Troubetzkoy, segundo a qual os fonemas, "sons linguisticamente significativos", constituem um "sistema de oposições", que, por seu turno, atualiza o sentido do "princípio de oposições" formulado por Saussure. Da mesma forma, podemos dizer que atravessa as definições acima a tensão entre o domínio das ciências naturais e o da ciência linguística, produzindo um efeito de distinção entre estes. Os fonemas, do lugar da ciência linguística, são concebidos como "sons linguisticamente significativos", e não apenas sons, eles possuem um conjunto de "traços distintivos" (do ponto de vista linguístico-gramatical) que os inserem no "complexo do som vocal" e que os individualizam, atribuindo-lhes "realidade gramatical".

d) Assim, tendo em vista o exposto, consideramos que a inclusão daquilo que Bechara coloca como "noções de fonêmica" configura-se como uma forma de resistência ao que postula o discurso oficial instituído/legitimado na/pela NGB, visto que o sentido hegemônico para o termo Fonética - o qual, como vimos, comparece no texto oficial -, que se impunha à época (e ainda hoje se impõe) nos estudos gramaticais brasileiros estava (está) filiado a uma abordagem biológica e, portanto, não linguística - do som.

\section{CONSIDERAÇÕES FINAIS}

Segundo Dias (1996), a gramática, enquanto tecnologia intelectual, coloca-se como uma projeção de completude, no sentido em que, ao produzir uma determinada realidade linguística, supõe dar conta $d a$ língua, descrevendo-a. Conforme o autor, tal projeção se sustenta em duas dimensões. A primeira diz respeito à produção do imaginário de unidade linguística que se funda como resultado da produção do que denomina efeito de idiomaticidade (DIAS, 1996). A segunda refere-se ao efeito de harmonia produzido entre as partes, efeito este que se dá a partir do gesto de interpretação/autoria procedido pelo sujeito ao se significar como gramático e, portanto, da sua identificação a determinado(s) domínio(s) teórico-metodológico(s), identificação esta que, como pontua o autor, "orienta desde questões como a relação entre conceito/regra e demonstração até a conformação dos capítulos do livro que lhe fornece o suporte" (DIAS, 1996, p. 184-185).

les marques distinctives des silhouettes des mots. Chaque mot doit contenir autant des phonèmes dans l'ordre voulu qu'il est nécessaire pour le distinguer de tout autre mot. Cette sucession de phonèmes n'est tout entière propre qu'à ce seul mot, mais chaque terme isolé de cette sucession apparait comme marque distinctive également dans d'autres mots" ([1939]1949, p 38). Sendo a fonologia tomada, a partir da distinção entre langue e parole formulada por Saussure, como uma ciência linguística que estuda os sons da língua (langue) - e não da fala (parole), como seria o caso da fonética - e considerando que, segundo seu ponto de vista, numa língua dada, entendida enquanto sistema, as oposições fônicas são empregadas para diferenciar as palavras, Troubetzkoy retoma, posteriormente, o conceito de fonema nos seguintes termos: "[...] le phonème est la somme des particularités phonologicament pertinents que comporte une image phonique" ([1939]1949, p. 40). 
Em nossa investigação, visando depreender como se dá a produção desse efeito de harmonia na primeira edição da MGP (1961) e, com isso, melhor compreender a função-autor nela colocada em funcionamento, procedemos a uma análise que, partindo do prefácio, adentra o corpo da gramática em busca de repetições e regularidades, silenciamentos, deslocamentos, paráfrases e polissemias. Como vimos, a primeira edição da MGP tem sua organização bem próxima da que propõe a NGB. A terminologia oficial divide a gramática em três partes: Fonética, Morfologia e Sintaxe, mais o que considera como apêndice. A MGP de 1961, salvo pequenas exceções, segue basicamente essa organização, o que evidencia a identificação do sujeito-gramático ao discurso oficial e o efeito deste sobre o discurso gramatical.

No entanto, como anunciado desde o prefácio da obra aqui analisada e como demonstramos ao analisar o comparecimento do termo fonêmica, sentidos filiados a outros lugares também se fazem presentes no dizer do gramático sobre a língua, caracterizando, assim, uma forma de resistência/ruptura em relação aos sentidos impostos pela NGB. Após a implementação da NGB, em 1959, para dizer sobre a língua na gramática, isto é, para ser gramático e, portanto, autor de gramática, faz-se preciso romper com os sentidos filiados à tradição gramatical anterior e filiar-se aos sentidos instituídos/legitimados pelo discurso oficial. Na MGP de 1961, contudo, tal imposição é contornada a partir da mobilização do argumento do novo, compreendido, sob essas condições de produção, como um argumento de cientificidade.

Instaura-se, assim, um segundo movimento de ruptura, agora com o que é posto como tradição, em prol de uma abordagem que leve em conta "os modernos estudos da linguagem", expressão esta que, como vimos, é polissêmica, já que ora parece estar associada, a partir dos nomes linguística americana e estudos fonêmicos, ao chamado estruturalismo, ora, a partir do que se tem por estudos estilísticos e da citação do nome de autor Said Ali, aos chamados estudos filológicos. É, pois, nesse jogo entre ruptura e manutenção dos sentidos impostos pela memória do discurso gramatical brasileiro que se constitui - no deslize entre o lugar do gramático e o do linguista - a função-autor que organiza a primeira edição da MGP.

\section{REFERÊNCIAS}

BALDINI, L. J. S. Nomenclatura Gramatical Brasileira: análise discursiva do controle da língua. Campinas, SP: Editora RG, 2009.

BECHARA, E. Moderna Gramática Portuguesa (curso médio) - com base na Nomenclatura Gramatical Brasileira. São Paulo: Companhia Editora Nacional, 1961.

BLOOMFIELD, L. Language (1933). New York: Henry Hold and Company, 1956.

CÂMARA JR., M. História da linguística (1975). 6. ed. Petrópolis, RJ: Editora Vozes, s.d.

CAVALIERE, R. (Org.). Entrelaços entre textos - Miscelânea em homenagem a Evanildo Bechara. Rio de Janeiro: Nova Fronteira, 2008.

COSTA, T. de A. da. Gramáticas pós-NGB: do discurso oficial a outros discursos (im)possíveis. 2010. 133 f. Dissertação (Mestrado em Língua Portuguesa) - Instituto de Letras, Universidade Estadual do Rio de Janeiro, Rio de Janeiro, 2010.

DIAS, L. F. Os sentidos do idioma nacional: as bases enunciativas do nacionalismo lingüístico no Brasil. Campinas (SP): Pontes, 1996. 90 p.

FOUCAULT, M. A ordem do discurso (1971). 15. ed. São Paulo: Loyola, 2007. 
GUILHAUMOU, J.; MALDIDIER, D. Efeitos do arquivo. A análise do discurso no lado da história. In: ORLANDI, E. P. (Org.). Gestos de leitura: da história no discurso. 2. ed. Campinas: Editora da Unicamp, 2010 .

GUIMARÃES, E. Apresentação - Maximino Maciel e um pouco de História. In: Revista Relatos 3, Jun. 1996. Disponível em: <http://www.unicamp.br/iel/hil/publica/relatos_03.html>. Acesso em: 10 ago. 2014.

“"História da gramática no Brasil e ensino". Relatos, n. 5, p. 7-13, out. 1997.

MACIEL, M. Breve retrospecto sobre o ensino da língua portuguesa (1910). Revista Relatos, 3, Jun.1996. Disponível em: <http://www.unicamp.br/iel/hil/publica/relatos_03.html>. Acesso em: 10 ago. 2014.

ORLANDI, E. P. Língua e conhecimento linguístico: para uma história das ideias no Brasil. São Paulo: Cortez, 2002.

Análise de Discurso - princípios e procedimentos. 7. ed. Campinas, SP: Pontes, 2007a. $2007 \mathrm{~b}$. Interpretação: autoria, leitura e efeitos de trabalho simbólico. 5. ed. Campinas, SP: Pontes,

Terra à vista - Discurso do confronto: velho e novo mundo. 2. ed. Campinas,

SP: Ed. da Unicamp, 2008a.

Discurso e Texto: formulação e circulação dos sentidos. 3. ed. Campinas, SP: Pontes, 2008 b.

PÊCHEUX, Michel. Semântica e discurso: uma crítica à afirmação do óbvio (1975). 4. ed. Campinas, SP: Editora da Unicamp, 2009.

PEREIRA, E. C. Grammatica expositiva. São Paulo: Weiszflog Irmãos, 1907.

SAUSSURE, F. Curso de linguística geral (1916). São Paulo: Editora Cultrix, 2006.

TROUBETZKOY, N. S. Principes de phonologie (1939) Traduit par J. Cantineau. Paris: Klincksiek, 1949.

\section{Recebido em: 24/06/15. Aprovado em: 27/10/15.}

Title: Considerations on the gesture of authorship in the Moderna Gramática Portuguesa (1961) by Evanildo Bechara

Authors: Thais de Araujo da Costa; Vanise Gomes de Medeiros

Abstract: Based on the theoretical approach of Discourse Analysis - Pêcheux e Orlandiin its relation with the History of Linguistic Ideas - Auroux e Orlandi -, this article has the objective of reflecting upon the production of the gesture of authorship in the first edition of the Moderna Gramática Portuguesa (1961), written by Evanildo Bechara. For this purpose, we will hold our analysis to the understanding of the effects produced in the grammarian's discourse by the presence of the term phonemic and to the apprehension of the process of distinction between this term and what was then phonetics and phonology.

Keywords: Discourse Analysis. History of the Linguistic Ideas. Grammar. Evanildo Bechara. Authorship.

Título: Consideraciones sobre el gesto de autoría en la Moderna Gramática Portuguesa (1961), de Evanildo Bechara

Autores: Thaís de Araujo da Costa; Vanise Gomes de Medeiros

Resumen: Basado en el aporte teórico del Análisis del Discurso - Pêcheux y Orlandi - en su relación con la Historia de las Ideas Lingüísticas - Auroux y Orlandi -, este artículo tiene por objetivo reflexionar sobre la producción del gesto de autoría na primera edición de la Moderna Gramática Portuguesa (1961), de Evanildo Bechara. Para ello, el análisis es detenido en la comprensión de los efectos del dicer del autor en razón del término "fonêmica" y en la comprensión del proceso de distinción entre este y lo que, entonces, se tenía por fonética y fonología.

Palabras-clave: Análisis del Discurso. Historia de las Ideas Lingüísticas. Gramática. Evanildo Bechara. Autoría. 